\title{
Chronic glaucoma: definition of the phenotype
}

The purpose of this article is to trace the development of the term 'chronic glaucoma' from early beginnings to the present day. I will look at the evolution of the term, what we mean by the term 'chronic glaucoma' today and how we might be defining it tomorrow.

\section{Evolution of the term}

Although descriptions of various eye diseases which probably included glaucoma have existed from antiquity, it was not until the seventeenth and eighteenth centuries that terms were used such as 'the eye has grown hard to the touch'1 or the hard eye with a 'sea green colour to the pupil'. ${ }^{2}$ This association of raised intraocular pressure (IOP) and disease led to an early attempt at control by puncture. Glaucoma at this time was the coexistence of a hard eye and visual loss.

In the nineteenth century considerable advances in our definition of what constitutes glaucoma were made, with the development of both the ophthalmoscope and the tangent screen and also with reproducible and increasingly accurate methods of measuring IOP. The near-simultaneous introduction of these methods of examination rapidly led to descriptions of many diseases of the eye. In glaucoma the changes at the optic disc were identified, described and later defined. The character, nature and extent of the visual loss were outlined on the tangent screen and by campimetry, while the range of IOPs seen in the normal and the glaucoma patient were identified. These features led to the concept of chronic glaucoma as a disease in which raised IOP caused visual field loss and glaucomatous cupping.

What caused the IOP to increase required some unravelling. It had previously been discovered that aqueous circulated through the eye and left via the trabecular meshwork. Histological examination of eyes removed with glaucoma and inflammation revealed angle closure. The introduction of gonioscopy ${ }^{3}$ allowed visualisation of the angle of the anterior chamber in the living eye. This examination showed partial angle closure to be associated with chronic glaucoma. Further studies suggested that pupil block was a prime cause of angle closure ${ }^{4}$ and that relief of the block by iridectomy could, in some cases, reverse the ocular hypertension. ${ }^{5}$

The cause of elevated pressure without angle closure remained a mystery. Trabecular 'sclerosis' was suggested, ${ }^{6}$ whereby progressive failure of the filtration system within the trabecular meshwork led to increased resistance and consequent elevated IOP to maintain aqueous flow. The site of the resistance was demonstrated first experimentally $y^{7,8}$ and then in enucleated human eyes., ${ }^{9,10}$ These discoveries allowed the subdivision of primary glaucoma into closed (usually associated with pupil block) and open (due to trabecular failure) varieties. Further refinement of the clinical features would allow better methods of diagnosis and management.

This classification of glaucoma varieties was advanced with the widespread application of the Schiotz tonometer in population surveys. These surveys identified the range of IOP found in the population and produced definitions of 'normal' and 'raised' IOP. Eyes with 'raised' IOP were deemed to have 'ocular hypertension'. Ocular hypertension was thought to lead to optic nerve change, and so ocular hypertension became in the eyes of many 'preglaucoma' requiring antiglaucoma treatment, ${ }^{11}$ a concept leading to extensive debate. ${ }^{12-15}$ More importantly it suggested that an IOP above the normal range was needed to make the diagnosis 'glaucoma', in conjunction with glaucomatous cupping and visual field loss.

This position, whereby most glaucoma was considered mechanical in origin with few cases not having increased IOP, remained the majority view until the late twentieth century. By that time a number of population surveys had revealed that $20-30 \%$ of all primary glaucoma patients in Caucasian populations had an IOP within the normal range (while for Japanese and other populations the proportion could be even higher). The relative risk for ocular hypertension alone did not rise to clinically significant levels until the IOP exceeded $30 \mathrm{mmHg}$. IOP ${ }^{16}$ was seen to be one facet of a multifaceted aetiology for chronic glaucoma, ${ }^{17}$ leaving elevated IOP to be downgraded to the status of risk factor.
R.A. Hitchings, FRCS, FRCOphth

Glaucoma Research Unit Moorfields Eye Hospital City Road London EC1V 2PD, UK 


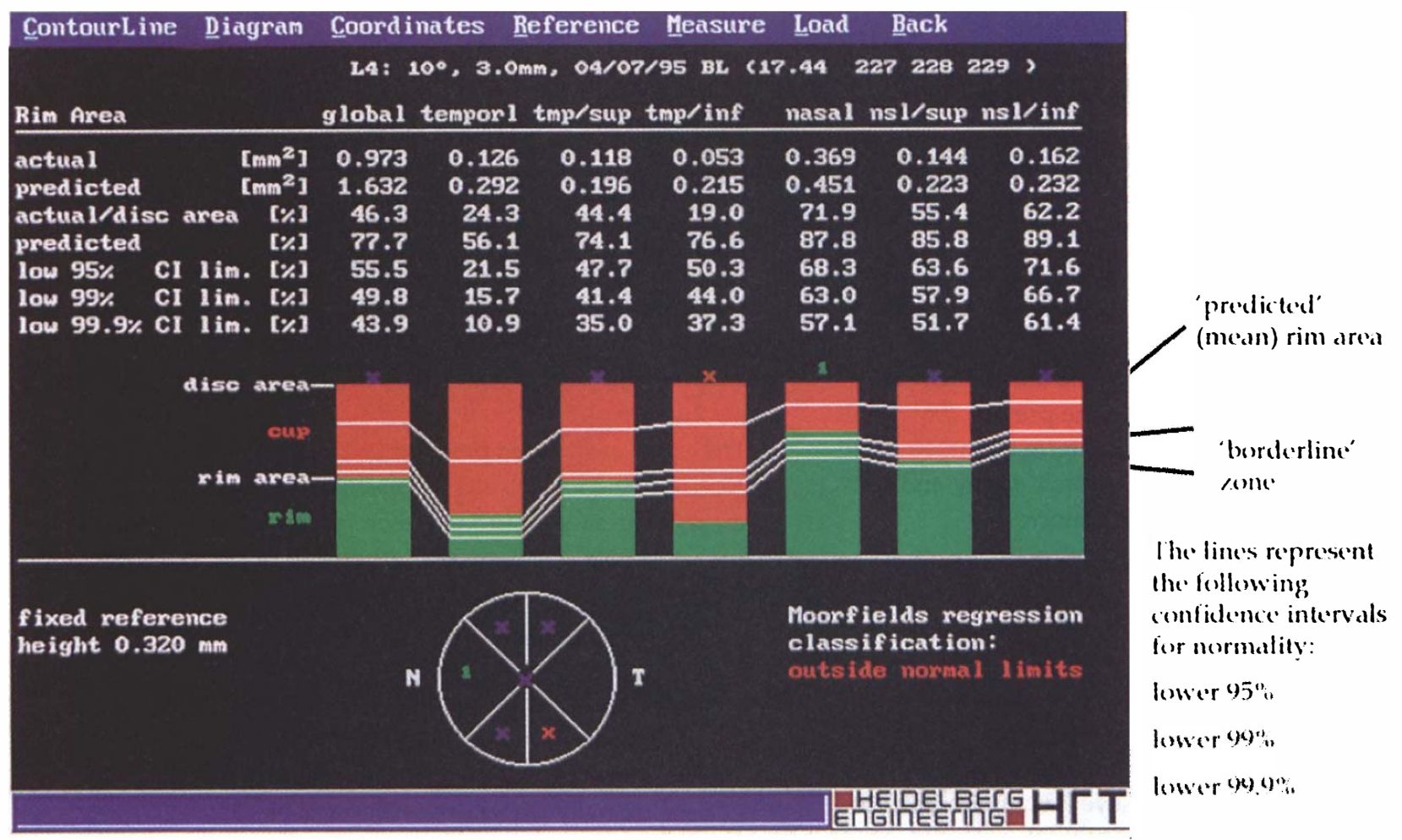

Fig. 1. Moorfields Analysis. The intuitive system for assessing the dimensions of the optic disc based on sector analysis of the neuroretinal rim area. The triple white lines crossing each red and green bar represent the likelihood of any of the named dimensions falling outside the normal range for a particular size of the optic disc.

So how do we define glaucoma today? It is an optic neuropathy involving loss of neurones within the optic nerve giving a characteristic deformation known as glaucomatous cupping. It will have an associated deficit in visual function and will have as a risk factor elevated IOP.

How will we diagnose glaucoma tomorrow? A major change in definition will come from the recognition that defective visual function may be hard to detect in the early stages of the disease. It is known that the development of glaucomatous cupping and defects in the retinal nerve fibre layer can predate the onset of visual field loss (as seen as defects on 'white on white' perimetry) by many years. ${ }^{18,19}$ Psychophysical tests, which assess different parts of the visual system, may be of value, but not in every case. The changes that make up the features of glaucomatous cupping have been typified $^{20,21}$ and of late quantified. ${ }^{22}$

The relationship between the optic disc and cup (which were described by Pickard in the $1920 \mathrm{~s}^{23}$ ) has been extensively discussed. It is known that optic discs can vary considerably in size. ${ }^{20}$ Segmental analysis of the optic disc, looking at both optic cup area and volume, and neuroretinal rim area and volume, have shown that
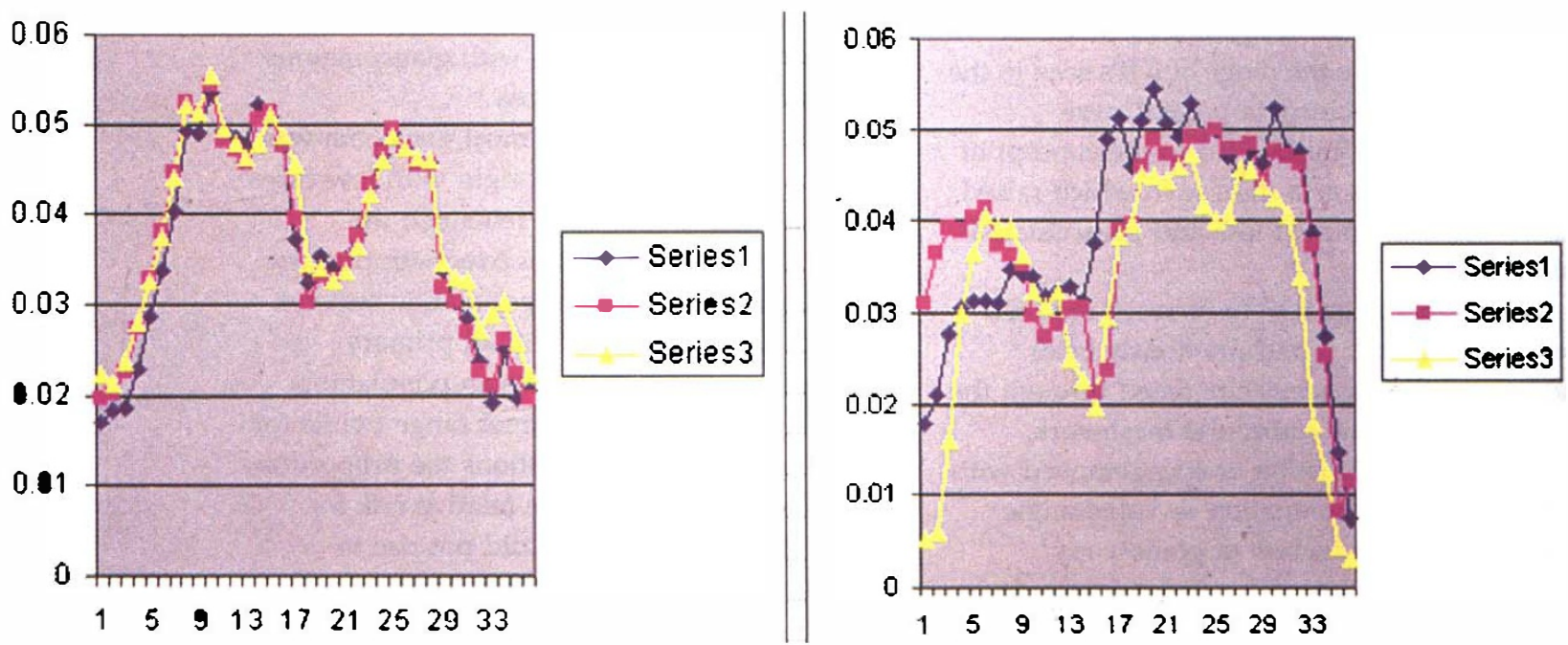

Fig. 2. Sequential optic disc change. The result of superimposing the segmental area measurements for the two optic discs from one patient taken on three annual occasions. In one eye there has not been any change at any of the measured sectors. The other eye demonstrates a sequential reduction in rim area over time. Thus progressive disease can be demonstrated. 
a linear relationship exists between the log of the rim area and optic disc size. ${ }^{24}$ This has allowed a definition of 'normal', 'suspect' and 'abnormal' optic discs based on individual disc segments. ${ }^{22}$ An intuitive grading system based on segmental analysis of the optic disc has been incorporated into the software of the scanning laser ophthalmoscope (Moorfields Analysis, Fig. 1), which automatically separates optic discs into these three categories. Although such a system will identify an optic disc whose dimensions fall outside the normal range, it will be up to the clinician to decide whether the abnormality is congenital or acquired - and, if acquired, whether due to glaucoma or other disease.

Many optic discs analysed by this method will be in the 'suspect' range. They may not have changed in appearance, or may have changed from glaucoma, but not yet have developed change in any sector that lies in an 'abnormal' category. The second part of any definition will be evidence for change or 'progression'. How can 'progression' be identified? Measurement data from sector analysis that show change outside the test-retest variation will be evidence for progression. Analysis of such data from sequential scanning laser ophthalmoscope images is shown in Fig. 2. Change in any sector of the optic disc can be due to disease progression, with thinning of the neuroretinal rim or regression (as can be seen with significant falls in IOP) with sector increase in the thickness of the neuroretinal rim.

Tomorrow's method of diagnosing glaucoma will be from measurement data. Glaucoma will be seen as an acquired deformity of the optic disc of characteristic appearance with either sector measurements that fall outside the normal range or evidence of progressive change in one or more sectors. These changes at the optic disc may be associated with evidence for visual loss, and may be associated with elevated IOP.

\section{References}

1. Bannister R. A worthy treatise of the eyes. London, 1622.

2. Platner JZ. Institutiones chirurgiae rationales cum medical cum manualis. Leipzig, 1745:889.

3. Salzmann M. Die Ophthalmoskopie der Kammerbucht. Klin Monatsbl Augenheilkd 1914;52:561.

4. Curran EJ. A new operation for glaucoma involving a new principle in the aetiology and treatment of primary glaucoma. Arch Ophthalmol 1920;49:131
5. Haas J, Scheie HG. Peripheral iridectomy in narrow-angle glaucoma. Trans Am Acad Ophthalmol 1952;56:589.

6. Barkan O. Glaucoma: classification, causes and surgical control. Am J Ophthalmol 1938;21:1099.

7. Baranay E, Scotchbrook A. The effect of testicular hyaluronidase on the resistance to flow through the angle of the anterior chamber. Acta Physiol Scand 1954;30:240-8.

8. Linner E. The outflow pressure in normal and glaucomatous eyes. Acta Ophthalmol 1955;33:101.

9. Grant WM. Experimental aqueous perfusion in enucleated human eyes. Arch Ophthalmol 1963;69:783-801.

10. Grant WM. Further studies of facility of flow through trabecular meshwork. Arch Ophthalmol 1958;60:523-33.

11. Leydhecker W, Akiyama K, Neumann HG. Der intraokulare Druck gesunder menschlicher Augen. Klin Monatsbl Augenheilkd 1958;133:662.

12. Pohjanpelto PEJ, Plava J. Ocular hypertension and glaucomatous optic nerve damage. Acta Ophthalmol 1974;52:194-201.

13. Kolker AE, Becker B. 'Ocular hypertension' vs open-angle glaucoma: a different view. Arch Ophthalmol 1977;95:586.

14. Phelps CD. Ocular hypertension: to treat or not to treat? Arch Ophthalmol 1977;95:588.

15. Chandler D, Grant WM. 'Ocular hypertension' vs open-angle glaucoma. Arch Ophthalmol 1977;95:585.

16. Wilson MR, Martone J. Epidemiology of chronic open angle glaucoma. In: Ritch R, Shields MB, Krupin T, editors. The glaucomas. 1st ed. St Louis: Mosby, 1996:753-68.

17. Quigley HA, Enger C, Katz J, Sommer A, Scott R, Gilbert D. Risk factors for the development of glaucomatous visual field loss in ocular hypertension. Arch Ophthalmol 1994;112:644-9.

18. Pederson JE, Anderson DR. The mode of progressive disc cupping in ocular hypertension and glaucoma. Arch Ophthalmol 1980;98:490-5.

19. Sommer A, Katz J, Quigley HA, et al. Clinically detectable nerve fiber atrophy precedes the onset of glaucomatous field loss. Arch Ophthalmol 1991;109:77-83.

20. Jonas JB, Gusek GC, Naumann GOH. Optic disc morphometry in chronic primary open angle glaucoma. Graefes Arch Clin Exp Ophthalmol 1988;226:522-30.

21. Jonas JB, Gusek GC, Naumann GOH. Optic disc morphometry in chronic primary open angle glaucoma. II. Correlation of the intrapapillary morphometric data to visual field indices. Graefes Arch Clin Exp Ophthalmol 1988;226:531-8.

22. Wollstein G, Garway-Heath D, Hitchings RA. Identification of early glaucoma cases with the scanning laser ophthalmoscope. Ophthalmology 1998;105:1557-63.

23. Pickard R. Alteration in the size of the normal optic disc cup. Br J Ophthalmol 1948;32:955.

24. Garway-Heath DF, Ruben ST, Viswanathan A, Hitchings RA. Vertical cup/disc ratio in relation to optic disc size: its value in the assessment of the glaucoma suspect. $\mathrm{Br} \mathrm{J} \mathrm{Ophthalmol}$ 1998;82:1118-24. 